\title{
Risk Factors for Surgery in Pediatric Patients with Crohn's Disease
}

\author{
Rayna Rumenova Shentova-Eneva ${ }^{a}$ Denitza Kofinova ${ }^{a}$ Petyo Hadzhiyski ${ }^{a}$ \\ Ekaterina Ivanova-Todorova ${ }^{b}$ Penka Yaneva ${ }^{a}$ Elena Lazarova ${ }^{a}$ \\ Mila Baycheva ${ }^{a}$
}

aDepartment of Gastroenterology and Hepatology, University Children's Hospital "Prof. Ivan Mitev,"

Medical University of Sofia, Sofia, Bulgaria; ${ }^{b}$ Department of Clinical Immunology, Laboratory of

Clinical Immunology, University Hospital "St. Ivan Rilski," Medical University of Sofia, Sofia, Bulgaria

\section{Highlights of the Study}

- Different demographic and clinical characteristics were investigated as potential risk factors for surgery in pediatric patients with Crohn's disease.

- Female sex, disease behavior, and the presence of perianal disease at diagnosis are associated with surgical intervention.

- Stricturing disease, stricturing and penetrating disease, and the presence of perianal disease at diagnosis are independent risk factors for surgery.

\section{Keywords}

Risk factors · Surgery · Pediatric Crohn's disease

\begin{abstract}
Objective: Pediatric Crohn's disease (CD) has a more aggressive phenotype and course than in adults. Many patients develop complications that require surgery. The aim of this study was to identify the factors associated with increased risk for surgical intervention in pediatric patients with $C D$. Subjects and Methods: This study is a retrospective review of medical records. We analyzed the following variables: sex, age at diagnosis, presenting symptoms, duration of symptoms before diagnosis, disease location and severity, the presence of extraintestinal manifestations, and the presence of anti-Saccharomyces cerevisiae antibodies. Univariate analysis using the Mann-Whitney test and Fisher's exact test was performed to detect the factors associated with surgery. Po-
\end{abstract}

tential risk factors with $p<0.05$ were further analyzed using a multivariate binary logistic regression model. Results: Fifty-seven patients ( 27 girls and 30 boys) were included in the analysis. More than one-fourth of them (28.1\%) required surgical management. Female sex $(p=0.043)$, disease behavior $(p=0.012)$, and the presence of perianal disease at diagnosis $(p<0.001)$ were the variables associated with surgical intervention. Stricturing disease (B2) (odds ratio [OR], 24.944; $p=$ $0.016)$, stricturing and penetrating disease (B2B3) (OR, 28.276; $p=0.011)$, and the presence of perianal disease at diagnosis (OR, 95.802; $p=0.001$ ) were independent risk factors for surgery. Female sex was associated with surgery without being an independent risk factor. Conclusion: Females with $\mathrm{B} 2$ or B2B3 or the presence of perianal disease at diagnosis are at a higher risk for surgery and should be considered for more aggressive medical treatments.

(c) 2022 The Author(s).

Published by S. Karger AG, Basel
C 2022 The Author(s).

Published by S. Karger AG, Basel

This is an Open Access article licensed under the Creative Commons Attribution-NonCommercial-4.0 International License (CC BY-NC) (http://www.karger.com/Services/OpenAccessLicense), applicable to the online version of the article only. Usage and distribution for commercial purposes requires written permission.
Correspondence to:

Rayna Rumenova Shentova-Eneva, rshentova@yahoo.com 


\section{Introduction}

Crohn's disease (CD) is an idiopathic, chronic inflammatory disorder whose predilection site for development is the terminal ileum, but it may affect any part of the gastrointestinal tract, from the mouth to the anus [1]. Approximately $10 \%$ of patients with $\mathrm{CD}$ are diagnosed in childhood [2]. Pediatric CD has been reported to have a more aggressive phenotype and course than in adults [3]. Early diagnosis and adequate therapy are essential for favorable outcome [4]. Exclusive enteral nutrition or medications are usually the first treatment option in pediatric patients with $\mathrm{CD}$, but they are not always enough, and some patients develop disease complications requiring further surgical management $[5,6]$. Early detection of patients at high risk for surgery is a key for choosing appropriate treatment to reduce bowel damage [6]. It is believed that early introduction of more intensive therapies (topdown strategy) might greatly benefit those high-risk patients, and they could avoid further surgery [4]. The aim of this study was to identify the factors associated with increased risk for surgical intervention in pediatric patients with CD.

\section{Subjects and Methods}

\section{Study Design and Participants}

We retrospectively reviewed the medical records of all patients with CD treated in our department in the period November 2011 to November 2020. In the final analysis were included the medical records of patients who were diagnosed by an experienced pediatric gastroenterologist following the standard criteria for the diagnosis of IBD in children and adolescents - the so-called Porto criteria $[7,8]$. The disease phenotype in all study participants was assessed according to the Paris classification - Pediatric Modification of the Montreal Classification for IBD [9]. With respect to the location, the disease was classified as ileal, involving the distal 1/3 ileum \pm limited cecal disease, colonic (L2), or ileocolonic. Involvement of upper gastrointestinal tract was defined as upper disease proximal to ligament of Treitz or upper disease distal to ligament of Treitz and proximal to distal 1/3 ileum. Disease behavior was categorized as nonstricturing and nonpenetrating, stricturing (B2), penetrating, and both penetrating and stricturing disease, either at the same or different times (B2B3). The presence of fistula, anal canal ulcers, or abscess was defined as perianal disease. With respect to age of the disease onset, there were two categories: Ala $=0-<10$ years and $\mathrm{A} 1 \mathrm{~b}=10-<17$ years. The impact of the disease on child growth was classified as no evidence of growth delay and growth delay.

We investigated the surgical rate and the type of surgery in the study population. As potential risk factors for surgery, the following variables were recorded: sex, age at diagnosis, presenting symptoms, duration of symptoms before diagnosis, disease location and severity, the presence of extraintestinal manifestations
(EIMs), and the presence of anti-Saccharomyces cerevisiae antibodies (ASCA). In addition, we analyzed the preoperative treatment received by our patients and investigated its impact of the surgical intervention.

\section{Statistical Analysis}

Data were processed and analyzed by an experienced statistical analyst using specialized statistical software (SPSS version 21.0; SPSS Inc, Chicago, IL, USA). The normal distribution was examined using visual (histograms and probability plots) and analytical methods (Kolmogorov Smirnov/Shapiro Wilk test). A $\chi^{2}$ test was used to compare proportions. A univariate analysis using the Mann-Whitney test and the Fisher's exact test was performed to explore the associations between individual variables and the risk for surgery. A $p$ value less than 0.05 was considered as statistically significant. The potential risk factors with $p<0.05$ were further analyzed. A multivariate binary logistic regression modeling was used to explore the relative contributions of the various risk factors. The odds ratio (OR) and $95 \%$ confidence interval were calculated. The goodness of fit was checked using the Hosmer-Lemeshow test, and the test results showed a good goodness of fit of the logistic regression model. All data were presented with tables. The continuous variables were presented as medians with ranges, whereas the categorical variables were summarized as the number of cases with the percentage (\%).

\section{Results}

\section{Characteristics of the Study Population}

In total, 57 patients ( 27 girls and 30 boys) were included in the final analysis. The median age of the study participants was 15 years (range 7-17 years). The most common presenting symptom at the time of diagnosis was abdominal pain (38.6\% of cases), followed by diarrhea (24.6\% of cases). The median duration of symptoms before diagnosis was 5 months (range 1-180 months). Most of our patients (64.9\%) had ileocolic location, 19.3\% of them had L2 and 15.8\% - ileal disease. Disease behavior was classified as nonstricturing and nonpenetrating, B2, penetrating, and $\mathrm{B} 2 \mathrm{~B} 3$ in $61.4 \%, 14.0 \%, 8.8 \%$, and $15.8 \%$ of the study participants, respectively. Approximately half of the patients (47.3\%) had upper gastrointestinal involvement: $36.8 \%$ had upper disease proximal to ligament of Treitz and $10.5 \%$ had upper disease distal to ligament of Treitz and proximal to distal $1 / 3$ ileum. Perianal disease had been diagnosed in $17.5 \%$ of the cases, and growth failure was confirmed in $14.0 \%$ of them. EIMs were observed in $63.1 \%$ of our patients. The most prevalent EIMs were anemia, growth failure, aphthous stomatitis, and arthritis. Positive ASCA were identified in $43.9 \%$ of the study participants. In $60.1 \%$ of the cases were detected both ASCA IgA and IgG antibodies, and in the rest 38.9\%, only ASCA IgG were positive. 
Table 1. Demographic characteristics and surgery-related factors of the patients

\begin{tabular}{|c|c|c|c|}
\hline \multirow[t]{2}{*}{ Variables } & \multicolumn{2}{|c|}{ Surgical intervention } & \multirow[t]{2}{*}{$p$ value } \\
\hline & Yes $(N=16)$ & No $(N=41)$ & \\
\hline Age at diagnosis, median (range) & $15(9-17)$ & $15(7-17)$ & 0.516 \\
\hline Duration of symptoms before diagnosis, median (range) & $7.5(3-48)$ & $4(1-180)$ & 0.062 \\
\hline \multicolumn{4}{|l|}{ Sex, $n(\%)$} \\
\hline Male & $11(68.8)$ & $16(39.0)$ & \multirow{2}{*}{0.043} \\
\hline Female & $5(31.3)$ & $25(61.0)$ & \\
\hline \multicolumn{4}{|l|}{ Presenting symptom } \\
\hline Abdominal pain & $9(56.3)$ & $13(31.7)$ & \multirow{4}{*}{0.366} \\
\hline Diarrhea & $2(12.5)$ & $12(29.3)$ & \\
\hline EIM & $2(12.5)$ & $8(19.5)$ & \\
\hline Other & $3(18.8)$ & $8(19.5)$ & \\
\hline \multicolumn{4}{|l|}{ Disease location } \\
\hline L1 & $4(25.0)$ & $5(12.2)$ & \multirow{3}{*}{0.430} \\
\hline L2 & $2(12.5)$ & $9(22.0)$ & \\
\hline L3 & $10(62.5)$ & $27(65.9)$ & \\
\hline \multicolumn{4}{|l|}{ Upper gastrointestinal involvement } \\
\hline No & $10(62.5)$ & $20(48.8)$ & \multirow{3}{*}{0.146} \\
\hline L4a & $3(18.8)$ & $18(43.9)$ & \\
\hline L4b & $3(18.8)$ & $3(7.3)$ & \\
\hline \multicolumn{4}{|l|}{ Disease behavior } \\
\hline B1 & $5(31.3)$ & $30(73.2)$ & \multirow{4}{*}{0.012} \\
\hline B2 & $3(18.8)$ & $5(12.2)$ & \\
\hline B3 & $3(18.8)$ & $2(4.9)$ & \\
\hline B2B3 & $5(31.3)$ & $4(9.8)$ & \\
\hline \multicolumn{4}{|l|}{ Growth failure } \\
\hline G1 & $1(6.3)$ & $7(17.1)$ & \multirow{2}{*}{0.419} \\
\hline G0 & $15(93.8)$ & $34(82.9)$ & \\
\hline \multicolumn{4}{|l|}{ Perianal disease at diagnosis } \\
\hline Yes & $8(50.0)$ & $2(4.9)$ & \multirow{2}{*}{$<0.001$} \\
\hline No & $8(50.0)$ & $39(95.1)$ & \\
\hline \multicolumn{4}{|l|}{ EIMs } \\
\hline Yes & $10(62.5)$ & $26(63.4)$ & \multirow{2}{*}{1.000} \\
\hline No & $6(37.5)$ & $15(36.6)$ & \\
\hline \multicolumn{4}{|l|}{ ASCA-positive } \\
\hline Yes & $10(62.5)$ & 15 (36.6) & \multirow{2}{*}{0.136} \\
\hline No & $6(37.5)$ & $26(63.4)$ & \\
\hline
\end{tabular}

EIM, extraintestinal manifestation; L1, distal 1/3 ileum \pm limited cecal disease; L2, colonic disease; L3, ileocolonic disease; $L 4 a$, upper gastrointestinal involvement proximal to ligament of Treitz; $L 4 b$, upper gastrointestinal involvement distal to ligament of Treitz and proximal to distal 1/3 ileum; B1, nonstricturing and nonpenetrating disease; $\mathrm{B} 2$, stricturing disease; $\mathrm{B} 3$, penetrating disease; $\mathrm{B} 2 \mathrm{~B} 3$, penetrating and stricturing disease; $\mathrm{G} 0$, no evidence of growth delay; G1, growth delay; ASCA, anti-Saccharomyces cerevisiae antibodies.

Risk Factors for Surgery

More than one-fourth of our patients (28.1\%) required surgical management. The surgical treatment involved intestinal resection ( $43.8 \%$ of the cases), strictureplasty (12.5\% of the cases), fistula excision (31.2\% of the cases), and abscess incision and drainage (12.5\% of the cases). Analyzing the different variables, we found that female sex, disease behavior, and the presence of perianal disease at diagnosis were the variables associated with surgical intervention in our patients (Table 1). Based on the results of the multivariate binary logistic regression model, disease behavior (the existence of $\mathrm{B} 2$ or B2B3) and the presence of perianal disease at diagnosis maintained their significance as independent risk factors for surgical management. Female sex was associated with surgery without being an independent risk factor (Table 2). 
Table 2. Multivariate binary logistic regression predicting independent risk factors for surgery

\begin{tabular}{lllll}
\hline Variable & OR & \multicolumn{2}{l}{$95 \% \mathrm{Cl}$ for OR } & $p$ value \\
\hline $\begin{array}{l}\text { Sex (female) } \\
\text { Disease behavior }\end{array}$ & 0.335 & 0.060 & 1.870 & 0.213 \\
$\quad 1.000$ & & & \\
$\quad$ B1 & 24.944 & 1.799 & 345.873 & 0.016 \\
$\quad$ B3 & 4.375 & 0.147 & 130.076 & 0.394 \\
$\quad$ B2B3 & 28.276 & 2.146 & 372.514 & 0.011 \\
$\begin{array}{l}\text { Perianal disease at } \\
\text { diagnosis, } p\end{array}$ & 95.802 & 6.780 & $1,353.779$ & 0.001 \\
\hline
\end{tabular}

$\mathrm{OR}$, odds ratio; $\mathrm{Cl}$, confidence interval; $\mathrm{B} 1$, nonstricturing and nonpenetrating disease; $\mathrm{B} 2$, stricturing disease; $\mathrm{B} 3$, penetrating disease; $B 2 B 3$, penetrating and stricturing disease.

Table 3. Noninterventional treatment of the study population

\begin{tabular}{llll}
\hline Therapy & \multicolumn{2}{l}{ All participants } & $p$ value \\
\cline { 2 - 3 } & $\begin{array}{l}\text { with surgery, } \\
n(\%)\end{array}$ & $\begin{array}{l}\text { without surgery, } \\
n(\%)\end{array}$ & \\
\hline Steroids & $14(87.5)$ & $35(85.4)$ & 0.838 \\
Immunomodulators & $15(93.8)$ & $39(95.1)$ & 0.844 \\
Anti-TNF & $12(75.0)$ & $21(51.2)$ & 0.105 \\
5-ASA & $1(6.25)$ & $18(43.9)$ & 0.007 \\
Antibiotics & $9(56.3)$ & $16(39.0)$ & 0.241 \\
EEN & NA & $5(12.9)$ & NA \\
\hline
\end{tabular}

Anti-TNF, antitumor necrosis factor; 5-ASA, 5-aminosalicylic acid; EEN, exclusive enteral nutrition.

\section{Noninvasive Treatments}

Analyzing the preoperative therapy of our patients, we found that most of them were treated with steroids before surgery, all but one received immunomodulators, and antitumor necrosis factor (anti-TNF) agents were administered in three fourths of the cases. In comparison, in the group without surgery, steroids were administered in $85.4 \%$, immunomodulators in $95.1 \%$, and anti-TNF in $51.2 \%$ of the cases. In both groups, most patients were exposed to more than one drug. Anti-TNF agents were administered as second- or third-line therapy. All patients on anti-TNF therapy also received immunomodulators (combination therapy). The median time to the surgical intervention for the patients treated with anti-TNF drugs was 5 months (range 1 month-36 months), compared to 2 months (1 month-3 months) for the patients without anti-TNF. The different types of noninvasive treatments before the surgery are presented at Table 3 .

\section{Discussion}

The natural history of CD is often characterized by progression to complications such as strictures, abscesses, or fistulas that may require surgical management. Predicting which patients are at increased risk for surgery is important, especially when choosing therapeutic agents and treatment strategies. In this study, we analyzed different demographic and clinical characteristics and one serological marker as potential risk factors for surgery in children with $\mathrm{CD}$. The results demonstrated that sex, disease behavior, and the presence of perianal disease at diagnosis were associated with surgical intervention.

Several studies have reported that younger age at the time of diagnosis was associated with decreased risk for surgery [10-12]. In contrast, Polito et al. [13] identified younger age at diagnosis as a risk factor for progression to complicated CD, defined as need for surgical intervention. Similar to Ryan et al. [14], our study found no association between age at diagnosis and later surgery.

Analyzing the time to diagnosis as a risk factor in a multicenter cohort study including 1,399 children with IBD, Ricciuto et al. [15] found that diagnostic delay was associated with a 2.5 -fold higher rate of complications, requiring surgical management. Although not achieving significance, our data suggest similar findings among our children with $\mathrm{CD}$. In our study population, the median duration of symptoms before diagnosis was marginally associated with surgery $(p=0.06)$.

There are conflicting data regarding the role of sex in relation to surgery. Our data agree with the findings of Gupta et al. [11] that females were at an increased risk for surgery compared to males. At the same time, other studies have shown no influence of sex on association with surgery $[10,16-18]$.

In this study, we failed to demonstrate a significant relationship between disease location and complicated CD, requiring surgical intervention. In contrast, some previous studies found an association between ileal location and complicated disease or surgery [14] and suggested that upper gastrointestinal tract disease and distal L2 decrease risk of surgery $[11,19,20]$. In our study, we also found no association between presenting symptom, the presence of EIMs or growth failure, and complicated CD or risk of surgery.

The present study confirmed the significance of disease behavior as an important risk factor for surgical intervention. Similar to previous reports $[11,14,21]$, we found that $\mathrm{CD}$ characterized by $\mathrm{B} 2$ or $\mathrm{B} 2 \mathrm{~B} 3$ behavior has been associated with higher rates of surgical interven- 
tions. In addition, we confirmed the significance of perianal disease as an independent risk factor for complicated disease and surgery $[11,14,22]$. Contrary to our results, Vernier-Massouille et al. [23] found no association between perianal disease and increased risk for surgery in pediatric patients with $\mathrm{CD}$.

Previous evaluations have linked the presence of ASCA to more complicated disease, including increased need for surgical interventions [11, 14, 22, 24]. Although our results failed to establish any association between ASCA positivity and increased risk of surgery, we noticed that more than $60 \%$ of our patients, who needed surgical intervention were ASCA-positive, and most of them (90\%) had ASCA titers $>6$ times the upper limit of normal.

The type of treatment administered to induce and maintain remission is an important factor that may impact the need for surgical management in the patients with CD. It is suggested that more aggressive treatments such as anti-TNF agents or a combination therapy (immunomodulators with anti-TNF) may reduce the surgical rate or extend the time to the first surgery in those patients [25-27]. Analyzing the therapy of our patients, we did not find any significant difference between the group with surgery and the group without surgery. However, when we focused on anti-TNF treatment, we established a longer time to surgery in the group of patients who received anti-TNF agents compared to those who did not receive anti-TNF therapy. Additionally, we may speculate that earlier introduction of anti-TNF drugs (a top-down approach) could be more beneficial to our patients regarding $\mathrm{CD}$-related surgery as in the studied population, they were administered always as second- or third-line therapy.

The past 2 decades have brought many advances in the treatment of patients with CD. Individualized therapies are gaining importance for successful disease management and a beneficial outcome. In this context, we believe the identification of patients at higher risk for surgery is essential for choosing an appropriate treatment and avoiding potential future complications.

This study reveals some of the factors associated with increased risk for surgery in children with CD. It has strengths but also limitations. The main strength of the study is that it adds new data to the existing knowledgebase about pediatric CD. Its main limitations are the single center retrospective design and the small sample size. In our country, pediatric care for patients with chronic disease is provided by specialists in corresponding referral centers. As our clinic is the biggest center for management of pediatric IBD in Bulgaria, we believe that the study results are valid and representative.

\section{Conclusion}

Despite its limitations, this is one of the few studies assessing the risk factors for surgery in pediatric patients with CD. Here, we demonstrated that female sex, the presence of perianal disease at diagnosis, and existence of B2 or B2B3 were associated with increased risk for surgery. Our findings support the current knowledge and suggest specific considerations for the health care professionals as they make therapeutic decisions for these patients.

\section{Acknowledgments}

The authors thank Todor Kundurzhiev for assistance with statistical analysis and Kalina Dimova for proofreading the article.

\section{Statement of Ethics}

The present study was conducted in accordance with the Declaration of Helsinki (as revised in 2013). According to the national law regulating research ethics and due to the retrospective design of the study, the ethical approval and informed consent have been waived since all analyzed data were collected as part of routine diagnosis and treatment, which were consistent with the current standard of care.

\section{Conflict of Interest Statement}

The authors have no conflicts of interest to declare.

\section{Funding Sources}

The authors did not receive any funding for this study.

\section{Author Contributions}

Conception and design: R.R.S.-E., P.Y., E.L., and M.B. Acquisition of data: R.R.S.-E., D.K., and P.H. Analysis and interpretation of data: R.R.S.-E., E.I.-T., P.Y., and M.B. Drafting: R.S., P.Y., E.L., D.K., and M.B. Critical revision and final approval: all the authors. 


\section{References}

1 Mamula P, Markowitz JE, Baldassano RN. Pediatric Inflammatory Bowel Disease. 2nd ed. Springer; 2013.

2 Ghione S, Sarter H, Fumery M, Laura A, Guillaume S, Delphine L, et al. EPIMAD Group. Dramatic increase in incidence of ulcerative colitis and Crohn's disease [1988-2011]: a population-based study of French adolescents. Am J Gastroenterol. 2018 Feb;113:26572.

3 Israeli E, Ryan JD, Shafer LA, Bernstein CN. Younger age at diagnosis is associated with panenteric, but not more aggressive, Crohn's disease. Clin Gastroenterol Hepatol. 2014 Jan; 12(1):72-9.e1.

4 Ungaro RC, Yzet C, Bossuyt P, Baert FJ, Vanasek T, D'Haens GR, et al. Deep remission at 1 year prevents progression of early Crohn's disease. Gastroenterology. 2020 Jul;159(1) 139-47.

5 Ruemmele FM, Veres G, Kolho KL, Griffiths A, Levine A, Escher JC, et al. Consensus guidelines of ECCO/ESPGHAN on the medical management of pediatric Crohn's disease. J Crohns Colitis. 2014 Oct;8(10):1179-207.

6 van Rheenen PF, Aloi M, Assa A, Bronsky J, Escher JC, Fagerberg UL, et al. The medical management of paediatric crohn's disease: an ECCO-ESPGHAN guideline update. J Crohns Colitis. 2020 Oct 7:jjaa161. Epub ahead of print.

7 IBD Working Group of the European Society for Paediatric Gastroenterology; Hepatology and Nutrition. Inflammatory bowel disease in children and adolescents: recommendations for diagnosis-the Porto criteria. J Pediatr Gastroenterol Nutr. 2005 Jul;41(1):1-7.

8 Levine A, Koletzko S, Turner D, Escher JC, Cucchiara S, de Ridder L, et al. ESPGHAN revised Porto criteria for the diagnosis of inflammatory bowel disease in children and adolescents. J Pediatr Gastroenterol Nutr. 2014 Jun;58(6):795-806.

9 Levine A, Griffiths A, Markowitz J, Wilson DC, Turner D, Russell RK, et al. Pediatric modification of the montreal classification for inflammatory bowel disease: the Paris cassifi- cation. Inflamm Bowel Dis. 2011 Jun;17(6): 1314-21.

10 Bernell O, Lapidus A, Hellers G. Risk factors for surgery and postoperative recurrence in Crohn's disease. Ann Surg. 2000 Jan;231(1): 38-45.

11 Gupta N, Cohen SA, Bostrom AG, Kirschner BS, Baldassano RN, Winter HS, et al. Risk factors for initial surgery in pediatric patients with Crohn's disease. Gastroenterology. 2006 Apr;130(4):1069-77.

12 Schaefer ME, Machan JT, Kawatu D, Langton CR, Markowitz J, Crandall W, et al. Factors that determine risk for surgery in pediatric patients with Crohn's disease. Clin Gastroenterol Hepatol. 2010 Sep;8(9):789-94.

13 Polito JM 2nd, Childs B, Mellits ED, Tokayer AZ, Harris ML, Bayless TM. Crohn's disease: influence of age at diagnosis on site and clinical type of disease. Gastroenterology. 1996 Sep;111(3):580-6.

14 Ryan JD, Silverberg MS, Xu W, Graff LA, Targownik LE, Walker JR, et al. Predicting complicated Crohn's disease and surgery: phenotypes, genetics, serology, and psychological characteristics of a population-based cohort. Aliment Pharmacol Ther. 2013 Aug;38(3): 274-83.

15 Ricciuto A, Mack DR, Huynh HQ, Jacobson K, Otley AR, deBruyn J, et al. Diagnostic delay is associated with complicated disease and growth impairment in paediatric Crohn's disease. J Crohns Colitis. 2021 Mar 5;15(3):41931.

16 Basilisco G, Campanini M, Cesana B, Ranzi T, Bianchi P. Risk factors for first operation in Crohn's disease. Am J Gastroenterol. 1989 Jul; 84(7):749-52.

17 Prantera C, Levenstein S, Capocaccia R, Mariotti S, Luzi C, Cosintino R, et al. Prediction of surgery for obstruction in Crohn's ileitis. A study of 64 patients. Dig Dis Sci. 1987 Dec; 32(12):1363-9.

18 Sedgwick DM, Barton JR, Hamer-Hodges DW, Nixon SJ, Ferguson A. Population-based study of surgery in juvenile onset Crohn's disease. Br J Surg. 1991 Feb;78(2):171-5.
19 Schaefer ME, Machan JT, Kawatu D, Langton CR, Markowitz J, Crandall W, et al. Factors that determine risk for surgery in pediatric patients with Crohn's disease. Clin Gastroenterol Hepatol. 2010 Sep;8(9):789-94.

20 Kim ES, Kwon Y, Choe YH, Kim MJ. Upper gastrointestinal tract involvement is more prevalent in Korean patients with pediatric Crohn's disease than in European patients Sci Rep. 2020 Nov 4;10(1):19032.

21 Splawski JB, Pffefferkorn MD, Schaefer ME, Day AS, Soldes OS, Ponsky TA, et al. NASPGHAN clinical report on postoperative recurrence in pediatric Crohn disease. J Pediatr Gastroenterol Nutr. 2017 Oct;65(4):47586.

22 Yarur AJ, Strobel SG, Deshpande AR, Abreu MT. Predictors of aggressive inflammatory bowel disease. Gastroenterol Hepatol. 2011 Oct;7(10):652-9.

23 Vernier-Massouille G, Balde M, Salleron J, Turck D, Dupas JL, Mouterde O, et al. Natural history of pediatric Crohn's disease: a population-based cohort study. Gastroenterology. 2008 Oct;135(4):1106-13.

24 Mitev S, Petkova M, Velikova T, IvanovaTodorova E, Shentova R, Yaneva P, et al. Prevalence of anti-Saccharomyces cerevisiae antibodies in bulgarian patients with Crohn's disease. C R Acad Bulg Sci. 2017 Feb;70(2):289.

25 Lichtenstein GR, Yan S, Bala M, Blank M, Sands BE. Infliximab maintenance treatment reduces hospitalizations, surgeries, and procedures in fistulizing Crohn's disease. Gastroenterology. 2005 Apr;128(4):862-9.

26 Ashton JJ, Borca F, Mossotto E, Coelho T, Batra A, Afzal NA, et al. Increased prevalence of anti-TNF therapy in paediatric inflammatory bowel disease is associated with a decline in surgical resections during childhood. Aliment Pharmacol Ther. 2019 Feb;49(4):398407.

27 Sakatani A, Fujiya M, Ito T, Inaba Y, Ueno N, Kashima S, et al. Infliximab extends the duration until the first surgery in patients with Crohn's disease. Biomed Res Int. 2013;2013: 879491. 